\title{
Desempenho de pastagem nativa e pastagem sobre-semeada com forrageiras hibernais com e sem glifosato ${ }^{1}$
}

\author{
Performance of native pasture and pasture sodseeded with winter species with or \\ without glyphosate
}

\author{
Luciana Melo Rizo² ${ }^{2}$ duardo Londero Moojen ${ }^{3}$ Fernando Luiz Ferreira de Quadros $^{4}$ \\ Francisco Leal Côrrea ${ }^{5}$ José Acélio Fontoura Júnior $^{6}$
}

RESUMO

O experimento foi desenvolvido em Bagé-RS, visando avaliar a produção de matéria seca (MS), taxa de lotação ( $k g$ de $P V h^{-1}$ ), ganho de peso vivo por animal (GMD, $\mathrm{kg} \mathrm{an}^{-1}$ dia $\left.^{-1}\right)$ e ganho por hectare ( $G P V$ ha $^{-1}$ ) em: $T_{1}$-pastagem nativa (testemunha); T2-pastagem nativa sobre-semeada com azevém (Lolium multiflorum), trevo branco (Trifolium repens) $e$ cornichão (Lotus corniculatus); $T_{3}$-semelhante ao anterior, mais aplicação de glifosato; $T_{4}$ - semelhante ao anterior, porém com adubação dobrada. Foram utilizados novilhos Braford. O sistema de pastejo foi o contínuo com ajustes na lotação para manter um nível de oferta de forragem de $10 \%$ (10kg de MS $\left.100 \mathrm{~kg} \mathrm{PV}^{-1} \mathrm{dia}^{-1}\right)$. Para a determinação da MS da pastagem, utilizou-se o método da dupla amostragem com uso de disco e para a determinação da taxa de acúmulo de MS, utilizou-se o método da gaiola de exclusão. As análises estatísticas foram feitas no programa SAS (1997). O delineamento experimental foi blocos inteiramente casualizados, tendo dois blocos e quatro tratamentos. A introdução de espécies hibernais em pastagem nativa com ou sem uso de glifosato contribuiu para aumentar a produtividade do campo nativo. A sobre-semeadura de espécies hibernais permitiu maior carga e ganho por animal e por área comparados com a pastagem nativa.

Palavras - chave: ganho médio diário, ganho por área, pastagem nativa, sobre-semeadura, herbicida.

\section{ABSTRACT}

The experiment was developed in Bagé-RS, Brazil, to evaluate the dry matter production (DM), stocking rate $(\mathrm{kg} L W$ ha

\begin{abstract}
$\left.{ }^{1}\right)$, live weight gain per animal ( $A D G, \mathrm{~kg} \mathrm{head}^{-1}$ day $^{-1}$ ) and gain per

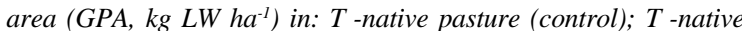
pasture sodseeded with Italian ryegrass (Lolium multiflorum'), white clover (Trifolium repens) and birdsfoot trefoil (Lotus corniculatus); $T$-similar to anterior, plus glyphosate spraying; $T$-similar to anterior, but with double fertilization. It were utilized Braford steers. The grazing method was the continuous stocking, with stocking adjustments to maintain a level of forage on offer of $10 \%(10 \mathrm{~kg}$ of DM $100 \mathrm{~kg} \mathrm{LW}$ day $\left.^{-1}\right)$. To determine the DM of pasture, it was utilized the double sample method with a disc meter and the cage method for the pasture accumulation rate. The experimental design was a complete randomized blocks, with two blocks and four treatments. The introduction of cool season species in native pasture, with or without glyphosate spraying, contributes to increase native pasture productivity. Over-seeding cool season species allowed a higher stocking rate and animal production per animal and per area as compared to natural pasture.
\end{abstract}

Key words: average daily gain, gain per area, native pasture, sodseeding, herbicide.

\section{INTRODUÇÃO}

A bovinocultura de corte e a ovinocultura dependem quase exclusivamente das pastagens nativas no Rio Grande do Sul. Estas pastagens ocupam uma área de cerca de onze milhões de hectares (IBGE, 1996), representando cerca de 37\%

\footnotetext{
${ }^{1}$ Extraído da dissertação de mestrado, apresentada pela primeira autora à Universidade Federal de Santa Maria (UFSM), Santa Maria, RS. Zootecnista, Mestre em Zootecnia, UFSM.

${ }^{3}$ Engenheiro Agrônomo, Doutor em Zootecnia, Professor Titular, Departamento de Zootecnia, Centro de Ciências Rurais (CCR), UFSM, 97105-900, Santa Maria, RS. E-mail: moojenel@terra.com.br, Autor para correspondência.

${ }^{4}$ Engenheiro Agrônomo, Doutor em Zootecnia, Professor Adjunto, Departamento de Zootecnia, CCR, UFSM.

${ }^{5}$ Engenheiro Agrônomo, Mestre em Zootecnia, Profissional liberal, Rua Professor Ivo Corseuil, 485 ap.202, 90690-410, Porto Alegre, RS.

${ }^{6}$ Zootecnista, Mestre em Zootecnia, Universidade Federal do Rio Grande do Sul.
} 
da área total do Estado. São caracterizadas por grande biodiversidade e por serem de crescimento tipicamente estival (BOLDRINI, 1997).

Sua produção de forragem se situa em torno de quatro t de MS ha'-1 ano $^{-1}$ (SCHOLL et al., 1976; MARASCHIN et al., 1997). Nesta pastagem, tem-se colhido ganhos de peso vivo por animal por dia (GMD) durante a sua estação de crescimento de cerca de 0,517kg e ganhos de peso vivo por área (GPV ha-1) de $146 \mathrm{~kg}$, com uma lotação média de $370 \mathrm{~kg}$ de peso vivo (PV) ha-1 (MARASCHIN et al, 1997). Sendo utilizadas ao longo de todo o ano, apresentam ganho na estação quente e perda na estação fria, e um baixo saldo favorável anual. Em diversas regiões fisiográficas do Estado, MOHRDIECK (1980) quantificou saldos de $\mathrm{G}_{\text {ha }}{ }^{-1}$ de 35,7; 85,9 e 86,5, respectivamente em Vacaria, São Gabriel e Uruguaiana.

Entre várias alternativas possíveis para enfrentar a estacionalidade produtiva das pastagens naturais, a introdução por sobre-semeadura de espécies hibernais com fertilizantes tem-se mostrado uma prática interessante para aumentar a produção de forragem e conseqüentemente os GMD e GPV ha-1. Neste sentido, SCHOLL et al. (1976) compararam a pastagem nativa com a mesma com introdução de aveia (Avena byzantina) + $90 \mathrm{~kg} \mathrm{ha}^{-1}$ de nitrogênio ou aveia + trevo vesiculoso (Trifolium vesiculosum), por sobresemeadura. A produção de forragem aumentou de 3346 para 9265 e $10139 \mathrm{~kg}$ de MS ha-1. Os GPV ha-1 foram de 90, 467 e $468 \mathrm{~kg}$, respectivamente, demonstrando grandes benefícios neste melhoramento de pastagem. Com misturas de aveia + azevém + trevo vesiculoso e aveia + azevém + ervilhaca (Vicia sativa), COELHO FILHO \& QUADROS (1995) conseguiram produções de 3469 e $3456 \mathrm{~kg}$ de MS ha-1, respectivamente, que possibilitaram o uso de cargas médias de 863 e $870 \mathrm{~kg}$ de PV ha-1, e colheitas de ganhos de 309 e 286 $\mathrm{kg} \mathrm{ha}^{-1}$ com GMD de 0,714 e 0,558kg.

Nos últimos anos, tem sido proposto o uso de herbicidas, especialmente o glifosato, para favorecer a introdução de espécies hibernais na pastagem nativa. Ocorre que, segundo CARÁMBULA (1997), este herbicida pode apresentar como desvantagem, em função da dose aplicada, a eliminação de algumas espécies produtivas, substituindo-as por espécies hibernais de baixa produção e favorecer o surgimento de espécies indesejáveis de pequeno porte.

O presente trabalho visa comparar a produção de forragem e produção animal da pastagem nativa e da mesma sobre-semeada com espécies hibernais sem e com o uso do herbicida glifosato, e com dois níveis de fertilização.

\section{MATERIAL E MÉTODOS}

O experimento foi conduzido na Estância da Bolsa, no município de Bagé, RS, de abril de 1999 a março de 2000. O solo da área é um Planossolo eutrófico (EMBRAPA, 1999). O clima da região, pela classificação de Köppen, é do tipo Cfa, subtropical úmido. A vegetação nativa é predominantemente de campos finos, com boa cobertura e com grande número de espécies de gramíneas e leguminosas.

Os tratamentos foram: $\mathrm{T}_{1}$ : pastagem nativa (testemunha); $\mathrm{T}_{2}$ : pastagem nativa com sobresemeadura de espécies e adubação; $\mathrm{T}_{3}$ : pastagem nativa com aplicação de glifosato, introdução de espécies e adubação; $\mathrm{T}_{4}$ : pastagem nativa com aplicação de glifosato, introdução de espécies e o dobro da adubação utilizada.

A área de pastagem nativa foi de 57,22ha, dividida em dez unidades experimentais. A aplicação de glifosato foi realizada nos dias 06 e 07/04/99, sendo utilizados 1,4kg ha-1 de glifosato (Round up WG) no $\mathrm{T}_{3}$ e $\mathrm{T}_{4}$. A semeadura foi feita a lanço, nos dias $22 \mathrm{e}$ 23/04/99, utilizando-se $45 \mathrm{~kg} \mathrm{ha}^{-1}$ de sementes de azevém, 9,5kg ha-1 de cornichão $c v$. São Gabriel e $1,9 \mathrm{~kg} \mathrm{ha}^{-1}$ de trevo branco $c v$. Zapicán. A adubação de base foi feita a lanço nos dias 23 a 25/04/99, de acordo com SIQUEIRA et al. (1987). Foi usado o fosfato monoamônico (MAP) para fornecer $89 \mathrm{~kg} \mathrm{ha}^{-1}$ de $\mathrm{P}_{2} \mathrm{O}_{5}$ e $17 \mathrm{~kg} \mathrm{ha}^{-1}$ de $\mathrm{N}$ no $\mathrm{T}_{2}$ e $\mathrm{T}_{3}$, e $178 \mathrm{~kg} \mathrm{ha}^{-1}$ de $\mathrm{P}_{2} \mathrm{O}_{5}$ e $34 \mathrm{~kg} \mathrm{ha}^{-1}$ de $\mathrm{N}$ no $\mathrm{T}_{4}$. A adubação nitrogenada de cobertura nos tratamentos com sobre-semeadura, no bloco “coxilha”, foi realizada nos dias 08 e 09/09/ 99. No dia 18/09/99 de 1999, fez-se a aplicação aérea nos tratamentos sobre-semeados no bloco "várzea”.

Foram utilizados $64,8 \mathrm{~kg} \mathrm{ha}^{-1}$ de $\mathrm{N}$ e 21, $6 \mathrm{~kg} \mathrm{ha}^{-1}$ de $\mathrm{K}_{2} \mathrm{O}$ na forma de uréia potássica. Os tratamentos com sobre-semeadura foram diferidos no dia 03/12/99, para garantir a ressemeadura natural das espécies introduzidas, voltando a ser utilizados em $09 / 02 / 00$. Os animais entraram na pastagem natural em 27/05/99 e nas demais em 22/09/99, apresentando uma massa de forragem de $1500 \mathrm{~kg}$ de MS ha-1.

As estimativas de MS da pastagem foram realizadas a cada 28 dias, seguindo o método de dupla amostragem com o uso de disco medidor. Em cada unidade experimental, foram feitos oito cortes, sendo quatro na parte interna de gaiola e quatro fora dela, medindo conjuntamente as respectivas alturas com um disco. Também foram feitas 60 leituras aleatórias por hectare em cada unidade experimental. Os cortes foram feitos com tesoura de esquilar, ao nível do solo.

O cálculo da MS foi obtido por meio de equações de regressão em cada avaliação com o valor 
da MS dos cortes e sua respectiva altura. A estimativa da taxa de acúmulo diário de MS foi feita a cada 28 dias, aproximadamente, com o uso de quatro gaiolas de exclusão ao pastejo por unidade experimental, conforme KLINGMAN et al. (1943).

O método de pastejo utilizado foi o contínuo, com lotação variável, para manter o nível de oferta de forragem pretendido de $10 \%$ (10kg de MS $\left.100 \mathrm{~kg}_{\text {de }} \mathrm{PV}^{-1} \mathrm{dia}^{-1}\right)$, utilizando-se a técnica "putand-take”, descrita por MOTT \& LUCAS (1952). Foram utilizados cinco animais “testers” e um número variável de reguladores por unidade experimental, conforme a necessidade de ajuste de carga. Os animais "testers” foram novilhos da raça Braford com idade média de 11 meses, peso médio inicial de $243 \mathrm{~kg}$ e final de $321 \mathrm{~kg}$. Os reguladores foram novilhos de raça, idade e peso semelhante aos animais "testers".

Os novilhos foram desmamados aos 56 meses, e mantidos em pastagem de azevém até entrarem nas pastagens cultivadas, sendo que os animais do $T_{1}$ vieram de campo nativo. Os animais reguladores que foram utilizados estavam em pastagens de azevém + trevo branco + cornichão, antes de entrarem no experimento. O ajuste da lotação foi baseado na estimativa da MS somada à taxa de acúmulo de MS, estimada no período imediatamente anterior, que era projetada para o período seguinte. O produto da soma resultou na estimativa da disponibilidade de MS dos potreiros. Os ajustes foram feitos a intervalos de aproximadamente 28 dias. As pesagens foram realizadas periodicamente, estando os animais em jejum de doze horas. O GMD foi calculado pela diferença entre o peso médio final dos novilhos "testers" e o seu peso médio inicial, dividido pelo período de tempo transcorrido a cada período e no total. A taxa de lotação foi obtida somando-se os pesos dos animais presentes em cada unidade experimental e dividindo este somatório pela área da unidade experimental, por período e na média. O GPV ha-1, em cada período, foi obtido multiplicando o ganho médio diário dos "testers" pelo número de animais $\mathrm{x}$ dia ha ${ }^{-1}$ em cada período. O GPV total foi obtido pelo somatório dos ganhos de peso vivo ha ${ }^{-1}$ dos períodos.

O delineamento experimental utilizado foi blocos completamente casualizados, com dois blocos escolhidos de acordo com o relevo do terreno e quatro tratamentos.

Os parâmetros estimados foram submetidos à análise da variância. Quando se observou diferença significativa foi realizado o teste de Tukey, utilizandose o programa estatístico SAS (1997). O nível máximo de significância aceito foi de 5\%.

\section{RESULTADOS E DISCUSSÃO}

A produção de MS dos tratamentos é apresentada na tabela 1 , onde se observa que variou de 3983 a $6997 \mathrm{~kg}$ de MS ha ${ }^{-1}$, sendo estes valores semelhantes aos encontrados em literatura. Houve diferença entre os tratamentos em dois períodos de avaliação e entre os tratamentos na produção total. No primeiro período de utilização dos tratamentos, com introdução de espécies, o $\mathrm{T}_{3}$ e $\mathrm{T}_{4}$ foram superiores aos demais, sendo o $T_{2}$ superior ao $T_{1}$. No último período, o $\mathrm{T}_{4}$ e $\mathrm{T}_{3}$ foram superiores aos outros, não havendo diferença entre o $\mathrm{T}_{1}$ e o $\mathrm{T}_{2}$. Essas diferenças entre os períodos se devem ao fato do $\mathrm{T}_{4}$ ter recebido o dobro da adubação, sendo que as mesmas ocorreram no início da utilização da pastagem e após diferimento. A produção total de MS somente incrementou com o uso da adubação em dobro, pois foi baixa a adubação nitrogenada nos demais tratamentos As produções obtidas em pastagem nativa são semelhantes às de SCHOLL et al. (1976) e MARASCHIN et al. (1997).

Avaliando a produção de aveia + azevém com e sem aplicação de glifosato, CAVALHEIRO (1997) obteve 4772, 5986, 6042 e $6278 \mathrm{~kg} \mathrm{ha}^{-1}$ de MS para a introdução sem herbicida, utilização de glifosato na dosagem de 1,5L ha ${ }^{-1}, 3,0 \mathrm{~L} \mathrm{ha}^{-1}$ de glifosato e 4,5L ha $^{-1}$ de glifosato, respectivamente. PEREZ GOMAR (1999), utilizando glifosato (4L ha ${ }^{-1}$ ) em pastagem de triticale ( $X$ Triticosecale) e azevém sobre-semeados em campo natural, observou que o uso do herbicida resultou em maior produção forrageira.

As taxas de lotação médias encontradas para os tratamentos com sobre-semeadura não diferiram entre si, com uma média de $1103 \mathrm{~kg}$ de peso vivo ha-1 ${ }^{-1}$ e foram todas superiores à pastagem nativa exclusiva ( $237 \mathrm{~kg}$ de $\mathrm{PV} \mathrm{ha} \mathrm{h}^{-1}$ ), o que pode ser observado na tabela 1 . A diferença entre o tratamento sem introdução e os outros foi em decorrência da produção de forragem ter sido maior com a introdução de espécies.

Na pastagem nativa, a taxa de lotação média utilizada de $237 \mathrm{~kg}$ de PV foi menor que a utilizada por MARASCHIN et al. (1997), que, para níveis de oferta de forragem de $4 \%$ a $16 \%$ de MS, em relação ao PV, mantidos durante quatro anos em pastagem nativa, utilizaram lotações médias de 370 $\mathrm{kg}$ de PV ha' ${ }^{-1}$. Esse valor é maior do que o obtido neste trabalho devido possivelmente, ao fato de a pastagem nativa ter sido usada desde o outono-inverno e não ter tido descanso. Também devido à diferença de composição florística dos campos de Bagé, em relação aos campos da Depressão Central, pode-se notar, todavia, que no período de primavera-verão, 
Tabela 1 - Produção de MS ( $\left.\mathrm{kg} \mathrm{ha}^{-1}\right)$, taxa de lotação ( $\left.\mathrm{kg} \mathrm{PV} \mathrm{ha}^{-1}\right)$, ganho médio diário $\left(\mathrm{kg} \mathrm{an}^{-1}\right.$ dia $\left.^{-1}\right)$ e ganho de peso vivo por área (kg ha $\left.{ }^{-1}\right)$ em pastagem nativa e pastagem nativa sobre-semeada com espécies de estação fria com e sem uso de glifosato. Bagé, 1999 2000 .

\begin{tabular}{|c|c|c|c|c|c|c|c|c|c|}
\hline Tratamento & $\begin{array}{c}27 / 05 \text { a } \\
26 / 06\end{array}$ & $\begin{array}{c}26 / 06 \text { a } \\
05 / 08\end{array}$ & $\begin{array}{c}05 / 08 \text { a } \\
22 / 09\end{array}$ & $\begin{array}{c}22 / 09 \text { a } \\
16 / 10\end{array}$ & $\begin{array}{c}16 / 10 \text { a } \\
12 / 11\end{array}$ & $\begin{array}{c}12 / 11 \text { a } \\
03 / 12\end{array}$ & $\begin{array}{c}03 / 12 \mathrm{a} \\
09 / 02\end{array}$ & $\begin{array}{c}09 / 02 \text { a } \\
15 / 03\end{array}$ & Total ou média \\
\hline \multicolumn{10}{|c|}{ Produção de matéria seca (kg ha $\left.{ }^{-1}\right)$} \\
\hline $\mathrm{T}_{1}$ & 85 & 85 & 65 & $597 c$ & 795 & 265 & 748 & 1437ab & 3983b \\
\hline $\mathrm{T}_{2}$ & & & & 1368b & 983 & 522 & 1092 & $1052 b$ & $5016 b$ \\
\hline $\mathrm{T}_{3}$ & & & & $1745 a$ & 1038 & 499 & 808 & $1677 a$ & 5766ab \\
\hline$\underline{\mathrm{T}}_{4}$ & & & & $1779 a$ & 1475 & 844 & 973 & $1928 a$ & $6997 a$ \\
\hline \multicolumn{10}{|c|}{ Taxa de lotação (kg PV ha ${ }^{-1}$ ) } \\
\hline $\mathrm{T}_{1}$ & 200 & 206 & 215 & $231 b$ & $229 c$ & $245 b$ & 271 & 298 & $237 b$ \\
\hline $\mathrm{T}_{2}$ & & & & 510ab & 1307b & $1431 \mathrm{a}$ & $*$ & 764 & 1003a \\
\hline $\mathrm{T}_{3}$ & & & & 535ab & 1522ab & $1655 a$ & $*$ & 409 & $1085 a$ \\
\hline $\mathrm{T}_{4}$ & & & & $664 a$ & $1740 \mathrm{a}$ & 1873a & $*$ & 604 & $1221 \mathrm{a}$ \\
\hline \multicolumn{10}{|c|}{ Ganho médio diário $\left(\mathrm{kg} \mathrm{an}^{-1} \mathrm{dia}^{-1}\right)$} \\
\hline $\mathrm{T}_{1}$ & 0,150 & 0,190 & 0,185 & 1,059 & 0,756 & 0,619a & 0,561 & $0,470 b$ & $0,465 c$ \\
\hline $\mathrm{T}_{2}$ & & & & 1,704 & 1,437 & 0,262ab & $*$ & 0,970a & $1,110 \mathrm{a}$ \\
\hline $\mathrm{T}_{3}$ & & & & 1,512 & 1,422 & 0,072ab & $*$ & $1,060 \mathrm{a}$ & 1,058ab \\
\hline $\mathrm{T}_{4}$ & & & & 1,529 & 1,482 & $-0,072 b *$ & $*$ & 0,800ab & $0,960 \mathrm{~b}$ \\
\hline \multicolumn{10}{|c|}{ Ganho de peso vivo por área $\left(\mathrm{kg} \mathrm{ha}^{-1}\right)$} \\
\hline $\mathrm{T}_{1}$ & 5 & 8 & 9 & $27 b$ & $19 b$ & 12 & 39 & $16 b$ & $134 b$ \\
\hline $\mathrm{T}_{2}$ & & & & 78ab & $191 \mathrm{a}$ & 27 & $*$ & $88 a$ & $384 a$ \\
\hline $\mathrm{T}_{3}$ & & & & 72ab & $209 a$ & 8 & $*$ & 53ab & $342 a$ \\
\hline $\mathrm{T}_{4}$ & & & & $92 a$ & $234 a$ & -9 & $*$ & $60 \mathrm{ab}$ & 393a \\
\hline
\end{tabular}

* Período de diferimento das pastagens cultivadas.

Médias seguidas de mesma letra na coluna não diferem significativamente $(\mathrm{P}>0,05)$.

$\mathrm{T}_{1}$ : pastagem nativa (testemunha)

$\mathrm{T}_{2}$ : pastagem nativa com sobre-semeadura de espécies e adubação;

T3: pastagem nativa com aplicação de glifosato, introdução de espécies e adubação;

T4: pastagem nativa com aplicação de glifosato, introdução de espécies e o dobro da adubação utilizada.

houve um aumento na capacidade de suporte da pastagem nativa.

Quando comparado com outros trabalhos, desenvolvidos no Rio Grande do Sul, observou-se que as taxas de lotação utilizadas foram maiores que as de QUADROS \& MARASCHIN (1987) que utilizaram taxas médias de 706, 682 e 525kg de PV ha- ${ }^{-1}$ em pastagens de aveia + azevém + trevo vesiculoso, azevém + trevo vesiculoso e azevém + trevo branco + cornichão, respectivamente. COELHOFILHO \& QUADROS (1995) quantificaram cargas médias de 863 e $870 \mathrm{~kg}$ de $\mathrm{PV}_{\text {ha }}{ }^{-1}$ para pastagens de aveia + azevém + trevo vesiculoso e aveia + azevém + ervilhaca, respectivamente. Trabalhando em pastagem de azevém, trevo branco e cornichão, em diferentes níveis de adubação, VIZZOTTO (1999) utilizou cargas médias de 766; 756 e 694kg de $\mathrm{PV}^{-1}{ }^{-1}$ para os níveis 150, 100 e 50\% da recomendação de adubação para RS e SC, respectivamente. Essa diferença deveu-se ao maior período de utilização das pastagens e à alta produção de cornichão e azevém.

Em trabalho semelhante conduzido em Alegrete por FONTOURA JÚNIOR et al. (2000), foram quantificadas lotações de 369, 501, 300 e $361 \mathrm{~kg}$ de PV $\mathrm{ha}^{-1}$ para os tratamentos pastagem nativa, pastagem nativa sobre-semeada, pastagem nativa sobre-semeada com uso de glifosato, pastagem nativa sobre-semeada com uso de glifosato, com o dobro da adubação, respectivamente. No presente trabalho, foi possível utilizar maiores lotações do que no desenvolvido em Alegrete, pois este recebeu fertilização nitrogenada enquanto o outro não, e também possivelmente por características intrínsecas da própria vegetação.

Analisando os dados da tabela 1, observase que houve diferença significativa $(\mathrm{P} \leq 0,05)$ entre os ganhos médios diários em dois períodos e na média. Todos os tratamentos com introdução foram

Ciência Rural, v.34, n.6, nov-dez, 2004. 
superiores à pastagem natural, devido à produção de forragem de qualidade durante o inverno.

Os GMD colhidos em todos os tratamentos com introdução são bons e equivalem aos citados por QUADROS \& MARASCHIN (1987), LESAMA (1997) e BALL et al. (1991).

Os GMD verificados em pastagem nativa sobre-semeada são considerados satisfatórios e equivalem aos encontrados por QUADROS \& MARASCHIN (1987), LESAMA (1997) e BALL et al. (1991), enquanto os GMD, verificados na pastagem nativa exclusiva, foram muito inferiores aos demais tratamentos, assemelhandose aos relatos por MARASCHIN et al. (1997). Para níveis de oferta de forragem de 4 a $16 \%$, coletados durante quatro anos, os referidos autores determinaram GMD de $0,517 \mathrm{~kg} \mathrm{an}^{-1} \mathrm{dia}^{-1}$. Isto mostra que os ganhos do presente trabalho foram melhores que os obtidos pelos autores citados devido às pastagens terem sido utilizadas sem descanso e os animais não perderam peso.

Em Alegrete, FONTOURA JÚNIOR et al. (2000) quantificaram ganhos diários de 0,25; 0,64; 1,$25 ; 0,73 \mathrm{~kg} \mathrm{an}^{-1}$ para os tratamentos pastagem nativa, pastagem nativa sobre-semeada, pastagem natural sobre-semeada com uso de glifosato no primeiro ano, pastagem nativa sobre-semeada com uso de glifosato nos três anos, pastagem nativa sobre-semeada com uso de glifosato nos três anos, com o dobro da adubação, respectivamente. Estes ganhos são inferiores devido à adubação nitrogenada feita nos campos de Bagé e não nos de Alegrete.

Os ganhos de peso vivo por área, apresentados na tabela 1 , mostram que houve diferença significativa na média entre os tratamentos, onde o $T_{2}, T_{3}$ e $T_{4}$ não diferiram entre si, e todos foram superiores ao $T_{1}$. Os ganhos obtidos em pastagem nativa (134kg ha-1) se assemelham aos de MARASCHIN et al. (1997), e os colhidos nas pastagens com introdução (entre 134 a 393kg ha-1) equivalem aos de COELHO FILHO \& QUADROS (1995) e SAIBRO \& SILVA (1999), e são inferiores aos de QUADROS \& MARASCHIN (1987).

Resultados obtidos na UEPAE/ Bagé - RS com uma mistura de cornichão + trevo branco + azevém, sobre campo nativo, chegaram a ganhos de $400 \mathrm{~kg} \mathrm{ha}{ }^{-1} \mathrm{ano}^{-1}$, com pastejo controlado (MARASCHIN, 1981). QUADROS \& MARASCHIN (1987) obtiveram ganhos por área de 515, 592 e 568kg de PV ha-1 em pastagens de aveia + azevém + trevo vesiculoso, azevém + trevo vesiculoso e azevém + trevo branco + cornichão, respectivamente. Os ganhos obtidos no presente trabalho são inferiores aos obtidos pelos autores citados, devido à ocorrência de deficiência de nitrogênio nas pastagens introduzidas, o que impossibilitou o uso das pastagens por maior período ocasionando menores ganhos.

Mais recentemente, em trabalho conduzido no campo nativo em Santa Maria, COELHO FILHO \& QUADROS (1995) introduziram misturas forrageiras de aveia + azevém + trevo vesiculoso e aveia + azevém + ervilhaca, e verificaram ganhos em novilhos de corte de $316 \mathrm{~kg} \mathrm{ha}^{-1}$ para gramíneas + trevo e $226 \mathrm{~kg} \mathrm{ha}^{-1}$ para gramíneas + ervilhaca. Com níveis de oferta de forragem entre quatro e $16 \%$, coletados durante quatro anos, MARASCHIN et al. (1997) obtiveram ganho ha${ }^{1}$ de $146 \mathrm{~kg}$ de PV em pastagem nativa.

Em pastagem de trevo branco e cornichão, em três regiões de melhoramento diferentes, no Uruguai, RISSO (1997) observou ganhos de 406, 485 e $551 \mathrm{~kg} \mathrm{ha}^{-1}$. BALL et al. (1991) detectaram ganhos de 394 e $463 \mathrm{~kg} \mathrm{ha}^{-1}$ em pastagens de centeio (Secale cereale) + azevém + trevo vesiculoso e azevém + trevo vesiculoso, respectivamente.

Em Alegrete, FONTOURA JÚNIOR et al. (2000) colheram 144, 96, 92 e $166 \mathrm{~kg} \mathrm{ha}^{-1}$ nos tratamentos pastagem nativa, pastagem nativa sobresemeada, pastagem nativa sobre-semeada com uso de glifosato no primeiro ano, pastagem nativa sobresemeada com uso de glifosato nos três anos, pastagem nativa sobre-semeada com uso de glifosato nos três anos, com o dobro da adubação, respectivamente. Os ganhos obtidos pelos referidos autores foram menores que os obtidos no presente trabalho, pois, em Alegrete, não foi feita adubação nitrogenada, o que refletiu em menores ganhos por área e por animal, devido a menor produção de matéria seca.

\section{CONCLUSÃO}

A adubação e introdução de espécies em pastagem nativa com e sem a aplicação do herbicida glifosato aumentou a produção de forragem. A sobresemeadura de espécies hibernais permitiu maior carga e ganho por animal e por área comparados com a pastagem nativa.

\section{REFERÊNCIAS BIBLIOGRÁFICAS}

BALL, D.M. et al. Southern forages. Atlanta, Georgia, USA, 1991. 256p.

BOLDRINI, I.I. Campos do Rio Grande do Sul: Característica fisionômica e problemática ocupacional. Boletim do Instituto de Biociências/UFRGS, Porto Alegre, v.56, p.1-39, 1997.

CARÁMBULA, M. Pasturas naturales mejoradas. Montevideo: Hemisferio Sur, 1997.

Ciência Rural, v.34, n.6, nov-dez, 2004. 
CAVALHEIRO, A. Sobre-semeadura de aveia (Avena strigosa) mais azevém (Lolium multiflorum) em campo natural com e sem o uso de herbicidas. 1997. 78f. Dissertação (Mestrado em Zootecnia) - Universidade Federal de Santa Maria.

COELHO FILHO, R.C.; QUADROS, F.L.F. de. Produção animal em misturas forrageiras de estação fria sobre-semeadas em uma pastagem natural. Ciência Rural, Santa Maria, v.25, n.2, p.250-256, 1995.

EMBRAPA. Centro Nacional de Pesquisa de Solos. Sistema brasileiro de classificação de solos. Rio de Janeiro : EMBRAPA, 1999. 412p.

FONTOURA JÚNIOR, J.A.S. et al. Desempenho animal em pastagem natural com diferentes alternativas de introdução de espécies de estação fria. In : REUNIÃO DO GRUPO TÉCNICO EM FORRAGEIRAS DO CONE SUL - ZONA CAMPOS, 18. 2000, Guarapuava, PR. Anais... Guarapuava, 2000. p.149150.

IBGE. Anuário Estatístico do Brasil. Rio de Janeiro, 1996. V.56, p.1-1-8-32.

KLINGMAN, D.L. et al. The cage method for determining consumption and yield of pasture herbage. Journal of American Society of Agronomy, Madison, v. 35, p.739-746, 1943.

LESAMA, M.F. Produção animal em gramíneas de estação fria com fertilização nitrogenada ou associadas com leguminosas, com ou sem fertilização nitrogenada. 1997. 129f. Dissertação (Mestrado em Zootecnia) - Universidade Federal de Santa Maria.

MARASCHIN, G.E. Oportunidades para uma eficiente produção animal baseada em pastagens. Revista Lavoura Arrozeira, Porto Alegre, v.34, n.330, p.10-25, 1981.

MARASCHIN, G.E. et al. Native pasture, forage on offer and animal response. In: INTERNATIONAL GRASSLAND CONGRESS, 18., 1997, Saskatoon Canadá. Proceedings... Canada, 1997. V.II, paper 288.
MOHRDIECK, K.H. Formações campestres do Rio Grande do Sul. In: FARSUL. SEMINÁRIO SOBRE PASTAGENS, 1980, Porto Alegre. Anais... Porto Alegre : FRSUL, 1980. p.18-27.

MOTT, G.O.; LUCAS, H.L. The design, conduct and interpretation of grazing trials in cultivated and improved pastures. In : INTERNATIONAL GRASSLAND CONGRESS, 6., 1952, State College, Pennsylvania. Proccedings... State College, 1952. p.1380-1385.

PEREZ GOMAR, E. Sistema solo-planta de campo nativo submetido ao uso de herbicidas para semeadura direta de forrageiras de estação fria. 1999. 87f. Dissertação (Mestrado em Agronomia) - Universidade Federal de Santa Maria.

QUADROS, F.L.F. de; MARASCHIN, G.E. Desempenho animal em misturas de espécies forrageiras de estação fria. Pesquisa Agropecuária Brasileira, Brasília, v.22, p.535-541, 1987.

RISSO, D.F. INIA La Estanzuela. Uruguai : INIA, 1997. p.16. (Série Técnica 83).

SAS INSTITUTE. SAS/STAT software: changes and enhancements through release 6.12. Cary : Statistical Analysis System Institute, 1997. 1167p.

SCHOLL, J.M. et al. Improvement of pastures by direct seeding into native grass in Southern Brazil with oats, and with nitrogen supplied by fertilizer or arrowleaf clover. Turrialba, San Jose, v.26, n.2, 1976.

SIQUEIRA, O.J.F. et al. Recomendações de adubação e calagem para os estados do Rio Grande do Sul e Santa Catarina. Passo Fundo : EMBRAPA - CNPT, 1987. 100p.

VIZZOTTO, V.R. Forrageiras de inverno sob pastejo em solo de várzea sistematizada, submetidas a níveis de adubação. 1999. 74f. Dissertação (Mestrado em Agronomia) - Universidade Federal de Santa Maria. 